\section{Recall of phonetically and semantically similar words by 3-year-old children*}

\author{
JOHN L. LOCKE and VIRGINIA L. LOCKE \\ Children's Research Center, Champaign, III., 61820
}

Thirty 3-year-old Ss recalled significantly more words in semantically similar ensembles than phonetically similar and control lists, suggesting that the symbolic value of words is a salient feature in the perceptual and memory behavior of children at this age.

In some previous work, 4-year-old children recalled more pictures whose labels rhymed than nonrhyming control pictures and the same pictures in nonrhyming sequences (Locke, 1971a). Since rhyme is described by a phonetic relationship which cannot reside in pictorial stimuli, it was deduced that Ss must have generated acoustic images spontaneously and identified the presence of rhyme through intertrace matching operations (Locke, 1971b). From this and other work (Locke \& Fehr, 1970; Flavell, 1971; Locke \& Locke, in press), it appears that short-term memory (STM) function in children is influenced by their use of stored phonological experience in prerecall processing.

The salience of phonetic cues in verbal learning continues into adulthood (see review in Locke, 1970) when semantic associations also are known to affect recall significantly (Bousfield, 1953). The relative importance of semantic and phonetic cues in STM for verbal stimuli has been studied in adults with equivocal findings that acoustic cues are more (Baddeley, 1966), less (Wickens \& Eckler, 1968), or as powerful (Carroll \& Horne, 1971) as semantic cues. Some other STM work has shown that phonetic features were generalized in paired-associate learning by $S$ s of 8 , 10,12 , and 20 years of age, and that semantic generalization was more apparent among the three older groups.

This paper reports an attempt to observe 3-year-old children's relative recall of briefly stored phonetically and semantically associated words. SUBJECTS

The Ss were 30 nursery school children, 12 males and 18 females,

*This research was supported by Public Health Research Grant MH-07346 from the National Institute of Mental Health. The authors are grateful to Busy Bee, Kiddie Kountry. Orchard Downs, and Mother's Moming Out nursery schools for providing Ss and assistance. whose ages ranged from 2.11 to 4.1 (mean: 3.4).

\section{STIMULI AND PROCEDURE}

Stimuli were three lists of 18 three-word ensembles with 10 Ss to a list. In each of the three lists there were six phonetic, semantic, and control ensembles with the first word in each ensemble identical across lists. List 1 began with a semantic ensemble (e.g., sun, moon, star), List 2 with a phonetic ensemble (e.g., sun, bun, gun), and List with a control series (e.g., sun, duck, plate). The order in which subsequent ensembles appeared was counterbalanced in each of the three lists. All of the words were familiar, based on our experience with other 3-year-olds, and all but one were monosyllabic. Stimuli were prerecorded and presented (Wollensak Model 1500) through a high-fidelity loudspeaker (Concertone Model SK-88) at a comfortable listening level in a moderately quiet section of Ss' school environment. Stimuli were presented with an interstimulus interval of approximately $3 \mathrm{sec}$. Following the third word in an ensemble was a 10 -sec rehearsal period, terminated by the word "Okay" on the test tape which also cued Ss to free-recall orally in the individually on a single occasion of approximately $10 \mathrm{~min}$ duration. The $\mathrm{Ss}$ were pretrained briefly to the task instructions and format prior to testing and were told they could have a small toy at the end of the task if they tried very hard to remember the words.

RESULTS AND DISCUSSION

The 30 Ss recalled a mean of 2.03 $(\mathrm{SD}=.44), 1.56(\mathrm{SD}=.38)$, and 1.54 (SD $=.47$ ) words of the three-word semantic, phonetic, and control lists, respectively. Following a significant overall effect $[F(2,87)=12.21$; $\mathrm{p}<.01]$, analysis of interlist recall differences showed the semantic lists to significantly exceed phonetic $(p<.01)$ and control $(p<.01)$ lists, with no significant difference between phonetic and control lists $(p>.05)$. Analysis of Ss' recall of words occupying the first position in lists ensuing 20-sec period. Each $S$ was seen (identical across ensembles) yielded a significant effect $[F(2,87)=7.35$; $\mathrm{p}<.01]$, with subsequent tests confirming the previously observed superiority of semantic recall over phonetic $(p<.05)$ and control $(p<.01)$ items.

One earlier study of children's paircd-associate learning showed greater phonetic than semantic generalization at Age 8, a discrepancy which attenuated somewhat with increasing chronological age (Rice \& Di Vesta, 1965). With 4-year-olds, there is some evidence that response-produced phonetic cues facilitate learning of lists of pictures whose labels rhyme (Locke, 1971a). A similarly facilitating effect was not found here with 3-year-olds who received aural stimuli. Although it appears on the surface that these studies, taken together, suggest a back-and-forth change in coding strategies with increasing age, such a conclusion must be tempered by the possibility that interexperiment differences in task structure and stimulus input may have produced this apparent switching effect. For example, the present study required free recall of aurally presented familiar words; Rice \& Di Vesta (1965) studied generalization using visually presented word and nonsense syllable pairs. In the meanwhile, it can at least be said from this experiment that the 3-year-olds' free recall of aurally presented words appeared to be facilitated by semantic and not phonetic intralist similarity, and that these young $S$ s were respectful of the symbolic value of language. They treated words as words, as units of reference and meaning, rather than nonrepresentational phonemic strings.

\section{REFERENCES}

BADDELEY, A. D. Short-term memory for word sequences as a function of acoustic. semantic and formal similarity. Journal of Experimental Psychology, 1966, 18. 362-365.

BOUSFIELD, W. A. The occurrence of clustering in the recall of randomly arranged associates. Journal of General Psychology, 1953, 49, 229-240.

CARROLL, D. \& HORNE, P. V. Semantic and acoustic labeling. Psychonomic Science, 1971, 22, 241-242.

FLAVELL, J. H. Developmental studies of mediated memory. In $H$. W. Reese and $L$. P. Lipsitt (Eds.), Advances in child development and behavior. Vol. 5. New York: Academic Press, 1970.

LOCKE, J. L. Subvocal speech and speech. Asha; $1970,12,7-14$.

LOCKE, J. L. Phonetic mediation in four-year-old children. Psychonomic Science, 1971 a, 23, 409.

LOCKE, J. L. Acoustic imagery in children's phonetically-mediated recall. Perceptual \& Motor Skills, 1971b, 32, 1000-1002.

LOCKE, J. L., \& FEHR. F. S. Young children's use of the speech code in a recall task. Joumal of Experimental Child Psychology, 1970, 10, 367-373.

LOCKE, J. L., \& LOCKE. V. L. Deaf 
children's phonetic, visual, and dactylic coding in a grapheme recall task. Journal of Experimental Psychology, in press.

RICE, U. M.. \& DI VESTA, F, J, A developmental study of semantic and phonetic generalization in paired-associate learning. Child Development, 1965, 36, 721-730.
WICKENS, D. D., \& ECKLER, G. R. Semantic as opposed to acoustic encoding in STM. Psychonomic Science, 1968, 12 , 63.

\section{CURRENT LITERATURE ON HUMAN MEMORY}

CHECKOSKY, S. F. (Lake Forest College, Lake Forest, III. 60045). Speeded classification of multidimensional stimuli. Journal of Experimental Psychology, 1971, 87, 383-388

CRAFT, J. L. (University of lowa, Iowa City, Iowa 52240), \& Hinrichs, J. V. Short-term retention of simple motor responses: Similarity of prior and succeeding responses. Journal of Experimental Psychology, 1971, 87, 297-302.

ELMES, D. G. (Washington and Lee University, Lexington, Va. 24450), \& Wilkinson, W. C. Cued forgetting in free recall: Grouping on the basis of relevance and category membership. Journal of Experimental Psychology, 1971, 87, 438-440.

FISHER, D. F. (Human Engineering Laboratories, Aberdeen Research \& Development Center, Aberdeen Proving Ground, Md. 21005), KARSH, R. Modality effects and storage in sequential short-term memory. Journal of Experimental Psychology, 1971, 87, 410-414.

MEDIN, D. L. (Rockefeller University, New York, N.Y. 10021), \& ROBBINS, D. Effects of frequency on transfer performance after successive discrimination training. Journal of Experimental
Psychology, 1971, 87, 434-436.

NELSON, D. L. (University of South Florida, Tampa, Fla. 33620), FOSSELMAN, J. R., \& PEEBLES, J. W. Words as phonological sequences. Journal of Experimental Psychology, 1971, 87, 361-366.

NORMAN, C. P., \& HALL, A. E. (College of Wooster, Wooster, Ohio 44691). Journal of Experimental Psychology, 1971, 87, 326-330.

RUNQUIST, W. N. (University of Alberta, Edmonton, Alberta, Canada). Stimulus coding and interference in paired-associate learning. Journal of Experimental Psychology, 1971, 87, 373-377.

SCHWARTZ, M. (University of Wisconsin, Madison, Wis. 53706). Subject-generated versus experimenter-supplied mediators in paired-associate learning. Journal of Experimental Psychology, 1971, 87, 389-395.

SCHWARTZ, M. (St. Francis Xavier University, Antigonish, Nova Scotia, Canada), \& BRYDEN, M. P. Coding factors in the learning of repeated digit sequences. Journal of Experimental Psychology, 1971, 87, 331-334.

STOFF, D. M. (Yeshiva University, New York, N.Y. 10003), \& EAGLE, $M$. N. The relationship among reported strategies, presentation rate, and verbal ability and their effects on free recall learning. Journal of Experimental Psychology, 1971, 87, 423-428.

TURNAGE, T. W. (University of Maryland, College Park, Md. 20742). Free recall of minimal serial lists. Journal of Experimental Psychology, 1971, 87, 378-382.

WALLACE, W. P. (University of Nevada, Reno, Nev. 89507), \& NAPPE, G. W. Re-pairing "rights" and "wrongs" in verbal discrimination learning. Journal of Experimental Psychology, 1971, 87, 355-360.

WEINSTOCK, R. B. (Mary Washington College of the University of Virginia, Fredericksburg, Va. 22401), \& DALY, H. B. Response learning association formation and repeated testing effects in a paired-associate task. Journal of Experimental Psychology, 1971, 343-347.

WILLIAMS, J. R. (Illinois State University, Normal, nl. 61761), LEVIN, I. P., \& NORMAN, K. L. Mediation effects in verbal chaining paradigms as a function of associative strength and the number of stages. Journal of Experimental Psychology, 1971, 87, 348-354. 